\title{
On the Symbolism of the Natural Objects in Tess of the d'Urbervilles
}

\author{
Chunxiao YUE $\mathrm{YU}^{1, \mathrm{a}}$ \\ ${ }^{1}$ Criminal Justice School, Henan University of Economics and Law, Henan, China \\ ${ }^{a}$ chunxiaoyue99protonmail.com
}

\begin{abstract}
Tess of the d'Urbervilles is British writer Thomas Hardy's most renowned novel and his sophisticated attempt on the technique of symbolism. This rural novel has been hailed as a masterpiece, symbolizing Hardy as a giant who achieved the clever combination of critical realism and symbolism.

This article attempts to explain the use of natural objects in "Tess of the d'Urbervilles" from symbolism. Through the approaches of literature research, explication, and analysis, this thesis seeks to explore the rich meaning of the natural objects reflected by the symbolic mechanism, and therefore to reveal the irreplaceable significance of symbolism in the novel.

In Tess of the d'Urbervilles, symbolism, especially natural things, has run through the entire novel. In terms of the physical properties, the natural objects in this thesis are classified into three types: heavenly, geographical and botanic objectives. Functioning to create atmosphere or to prefigure the future, all three types that appear in different contexts and change constantly meaning with the storyline are equally significant. Through these methods, the novel can more vividly narrate the story and the characteristics of the heroine rather than directly describe. This article will discuss the use of symbolism in Tess of the d'Urbervilles from the above three aspects, analyze Tess's tragic fate and the remarkable artistic effect of this novel.
\end{abstract}

Keywords: symbolism, natural objects, Tess's fate.

\section{INTRODUCTION}

Thomas Hardy (1840-1928), an English writer who was not only the successor carrying on the English tradition but one of the pioneers of critical realism literature, had been renowned for his creativeness in demonstrating the landscape in Victorian Britain through writing novel in a unique way, to consolidate and enrich which, he extensively used literature skills including symbolism, making his works show marvelous artistic charm. Tess of the d'Urbervilles, which is acknowledged as the greatest masterpiece of both Hardy and British literature, enjoys a remarkable reputation for its expert use of symbolism.

The researches on Tess of the d'Urbervilles show great prosperity both at home and abroad. In foreign academic community, researchers started studying Tess of the d'Urbervilles in 1910 from an assort of crossdisciplinary perspectives including law, sociology, pedagogy, dramatic art and so forth, which is nearly fifty years earlier than Chinese scholars. In China, there has been researching on Tess of the d'Urbervilles since 1959, compared with the former, Chinese scholarly person attach more importance to language itself, especially to rhetorical devices, among which quite a few studies focus on the symbolism objects in this book, which dose help expose Tess's pathetic fortune. By way of illustration, $\mathrm{Wu}$ and Wang produce a paper about the symbolism of the sun, arguing that it contains three distinct symbolizing meanings in Tess of the d'Urbervilles: Hope and goodness; suffering and death; passion and destruct, which helps put Tess in a broader cultural and historical context, reflecting the sicknesses and anachronism of time and analyzing the deep reasons of the feature's deplorable fate. Using the historical analysis and logical analysis, Wang has a study on gharry in his essay "The Symbolic Meaning and Function of the Gharry in Tess of the d'urbervilles", conveying the idea that, acting as a symbolic object, the gharry appearing in different spots plays a pivotal role in driving the plot, strengthening the strong feeling of melancholy, and making Tess's tragic image-building. And the work on the symbolism of animals, has been 
taken by $\mathrm{Wu}$ and $\mathrm{Ma}$ in their writing "On the symbolism of animals in Tess of the d'Urbervilles", in which paper they indicate that the bird in this book symbolizes mildmannered Tess and her love, whose song also signifies Tess's mood swings. Also, Chen develops a intense discourse about symbolism by studying various objects such as names, sites and colors, and supposes that the usage of symbolism can be termed as the most distinctive characteristic in this novel, which does great good to both highlighting the theme and enhancing the artistic appeal. In these compositions, although critics explore the symbolism in Tess of the d'Urbervilles from comprehensive views and put forward an association between symbolism and Hardy's works, there have been few empirical investigations into symbolism from specific perspectives, especially for the symbolism of natural objects. This thesis will generate fresh and special insight into the symbolism, attempting to clarify the theme and Tess's destiny by the means of dissecting the symbolic implication of various natural targets in this fiction on the basis of previous studies.

Composed of only three themed chapters, this thesis begins by discussing the theoretical foundation, namely, the definition of symbol, symbolism as well as the distinction and connection between them, it will then go on to construing the symbolism of natural objects in detail, such as the stars, the water and the plants as well, which is also the main body of the thesis and aiming at reasoning Tess's tragical lot. The last chapter is concerned with the conclusion, and the author of the thesis will sum up the effect that the symbolism produces in this book and stress the importance of its using.

\section{SYMBOLISM IN LITERATURE FIRST LEVEL HEADING}

\subsection{Symbol}

The symbol is a wide-reaching concept with more than complicated connotations and involves a wide range of branches. For Lian, the symbol indicates mathematical symbols and computer codes from the view of natural science or engineering. At the same time, in the linguistics field, it signifies the basic language unit. Further western liberal art, it refers to a sort of rhetorical device and a genre, an archetypal structural unit, and sometimes, even a notion equating with the noumena of the art. On the question of the development of symbol, first, a symbol in Greek merely means a token that represents friendship, and then it became a kind of matter assisting with the interaction between human beings and gods, whose semantics consists of artificiality and convention while working as either a token or an agent between gods and men. However, with the prosperity of French symbolism, the inner meaning and theoretical status of symbols have undergone significant changes. Specifically, a symbol has transferred from a conventional term into a more vivid technique of liberal arts, from an ordinary notion into one that plays a crucial part in theory and literature.

\subsubsection{Symbolism}

Symbolism is a genre of literature that evolved from symbolism. It is also a specific literary trend that expresses ideas and emotions by suggesting rather than directly describing or defining who they are. $\mathrm{Li}$ especially pointed out that symbolism can be said to be the earliest and most authoritative school of European and American modernist literature. It was first embodied in the poetry, which the famous Frenchman Bodler initiated in the $1850 \mathrm{~s}$, and then developed under the dedication of Glenn and Malam. The artistic claim and aesthetic principle of symbolism include the exploration towards humanitarianism and mysticism, the criticism of bourgeois society, the confirmation of individuality, and the pursuit of the expressional forms of modernist as well. Unlike naturalism, which tends to imitate the external material world, symbolism mainly focuses on inner spiritual discourse, explaining why symbolism is considered an example of resistance to boring naturalism. According to this, symbolism can explain that an objective item corresponding to a particular meaning or idea can be captured in daily life or the surrounding environment. What is more, for $\mathrm{Li}$ Ka-Shing, symbolism is not just a rhetorical device but a composition rule, a literary spirit, and even the essence of art. Therefore, there is a certain degree of uncertainty around it. The term is symbolism because it is too broad.

\subsubsection{Symbol and Symbolism}

For the difference and the connection between Symbol and Symbolism, Sun lists the main features of which as follows: Symbolism, as mentioned above, is an inventive approach highly close to the world view and constantly, referring to a type of thinking trend in literature and art in the nineteenth and twentieth-century and the theoretical concept of which includes musicality, suggestion, and mystery, whereas a symbol is a technique that is quite specialized and communicatory in artistic producing, acting on words or phrases which helps indicate a target that, in turn, symbolizes something beyond itself, or has a series of references.

Nevertheless, symbolism does share plenty of similarities with the symbol. The two terms are both the basis of correspondences: the belief that there are inner and organized inferences between the human mind and the external world, also between the natural world and the spiritual world, and that provokes the hallucinations of the human mind and intimates the secrets of the inner world. In addition, the symbol is indeed an essential intermediary of symbolism, and only through which can symbolism achieve its artistic pursuing of musicality, 
suggestion, and mystery. At the same time, symbolism literature considers symbolism as an aesthetic principle and seeks to grasp the world from an aesthetic perspective.

\section{SYMBOLISM OF THE NATURAL OBJECTS IN TESS OF THE D'URBERVILLES}

Instead of depicting the plots directly, Hardy gives full play to his artistic imagination with the aid of symbolism in various respects, especially in natural objects, as Varley acclaims, making Tess of the d'Urbervilles a breathtakingly poetic and allegoric work that has got a profound theme, from which there are a considerable number of elements worthy learning [2].

\subsection{Symbolism of the Sun}

In many countries, as in Britain, the sun is the symbol of youth. It can be seen that in the traditional annual club carnival of Marlott Village "May Day Ball", bathed in the lovely sunshine of Tess and other young girls seem to be as vibrant as light, in such an atmosphere. In their prime, it is the sun that ignites their aspirations and expectations for the future, making them realize that they are like the sun, not only young and aggressive but also cheerful and progressive, "ideal and reality collide, just like the sun. Illumined their shadows "(7). Tess was one of them, enjoying this glow of freshness and prosperity, through which she was encouraged to explore the unknown, though uncertain, and to expect.

However, in some other circumstances, the sun is also equal to the ending of life. When Tess and her brother transported the hives to Casterbridge, their equipment was destroyed by a mail car flying like an arrow, causing the horse to sink. "The huge pool of blood in front of her has shown a condensed rainbow color, and when the sun has risen, it reflects a hundred prismatic tones" (27). The sun's brilliance at this time is no longer simply shining, but the beauty that signs death. Likewise, the day that Tess was arrested, "All waited in the growing light, their faces and hands as if they were slivered......Soon the light was strong, and a ray shone upon her unconscious form, peering under her eyelids and waking her" (392), the dawn slowly shone on Tess's sleeping body, gradually immersing her in the light, symbolizing death is coming step by step.

\subsection{Symbolism of the Mist}

Niu emphasized that mist is a kind of astronomical material, which happened in Tess's lifetime when some crucial things happened. The symbolic import of the misty fog is tremendously profound, as the mist itself has mysterious symbolic meaning, symbolizing the hard times of Tess's life. The day Tess was seduced by Alec d'Urbervilles was a misty night, and with her considerable absent-mindedness or sleepiness, she failed to perceive that Alec had taken the wrong track. "till a faint luminous fog, which had hung in the hollows all the evening, became general and enveloped them. It seemed to hold the moonlight in suspension, rendering it more pervasive than in clear air" (Hardy 66).

Subsequently, Tess slept soundly and could not wake up. Unfortunately, she was invaded by Alec d'Urbervilles. "he plunged into the webs of vapour which by this time formed veils between the trees......but by this time the moon had quite gone down, and partly on account of the fog. The Chase was rapped in thick darkness, although morning was not far off" (70). The dulling fog shares the resemblance with the invisible net that covers innocent Tess, which typifies the hypocritical social morality and the vicious power, implying that the road of life is full of dangers, the morning did not come at last, nevertheless not far away, Tess's life, almost to the end of which, is enclothed with a layer of shade that is hard to step out.

\subsection{Symbolism of the Valley}

The beautiful Blackmoor Valley is an encircled and secluded area, and most of its area is still untouched. Amidst the ups and downs of its northeast is Mallot, a paradise village, a piece of undeveloped Primitive land, used to symbolize Tess, a "real country girl who is not used to many eyes" (Hardy 8), as flawless as mentioned earlier, "Tess de Bayfield was just a woman at this time in her life. An emotional container without experience" (9). Besides, the large amount of description of solid colors such as green or blue in Blackmoor also implies Tess's plainness as the color of that landscape.

At the end of the first chapter, Tess, who needs to make money to purchase a new horse for her father, set off for Trantridege in June, which is the beginning of her wretchedness. On the way to Trantridege, "Rising still, an immense landscape stretched around them on every side, behind, the green valley of her birth, before, a gray country of which she knew nothing except from her first brief visit to Trantridege" (47). The landscape in the valley indicates the vita that Tess has experienced in the past and that she is going to confront in the future: The valley in which she was born is green, and it is a sign that Tess's life at that stage is vivacious and full of hope, whereas the field, which she has not yet been familiar with, is grey, foreshadowing the gloom and doom that will befall Tess shortly. Besides, the transition of color suggests Tess's migration from Marlott to Trantridege, as the novel shows that she would be pushed into the bottom of life by Alec soon afterwards, her fortune is venturing from verdancy into darkness. 


\subsection{Symbolism of the Waterweed}

The symbol of waterweed is also mirrored in Tess of the d'Urbervilles, which gives readers a deep impression. The morning that the men and maids of the dairy were gathering to have breakfast, they talked about a couple whose situation is similar to Tess's. Tess, who hardly could bear their mirth, went out of the door, stepping to the mainstream of the Froom River. "Men had been cutting the water-weeds higher up the river, and masses of them were floating past her--moving islands of green crow-foot, whereon she might almost have ridden" (176). The aquatic plant here is also a simile, which refers to people's gossips that echoes around her like the weeds floating on the water surface. Moreover, the word "ridden" is the past participle of the verb ride and an adjective, meaning to be abused or disturbed, which shows that Tess has been distraught and spoiled by people's scandals and ridicule, which puts her at a disadvantage.

\section{CONCLUSION}

Tess has become one of the most iconic characters in British literature because of the rich metaphorical and symbolic nature used upon her, which is "both the aim and the result of artistic creativity". It also makes Hardy a world-renowned writer, since, as is commentated by Nie in her book, he inherits the tradition of critical realism while irritating the use of symbolism ideally [4]. This project investigates the effect of the symbolism of the natural targets classified into three categories according to the properties. The author of this thesis attempts to broaden the previous study of Tess of the d'Urbervilles by integrating the main symbols in the novel into a complete whole [5]. The author assumes that by incorporating the symbols in this novel, the theme can be better brought out, more importantly, Hardy's endowment of producing profound meaning in both linguistics and structural respect.

Regrettably, this study has missed out on the symbolic meaning of the zoological objects owing to the limit on the characters in academic writing. Notwithstanding the relatively weak points, this work offers valuable insights into the validity of the environmental description, which will undoubtedly foster people's comprehension of the symbolism of natural objects. The focus on the symbolic meaning of time objects and the symbolic meaning of color objects will be a fruitful field for future research. In this way, not only can a more in-depth study of the novel's content, but also a more effective study of rhetoric techniques, especially symbolism.

\section{AUTHORS' CONTRIBUTIONS}

The title "AUTHORS' CONTRIBUTIONS" should be in all caps.

\section{ACKNOWLEDGMENTS}

This thesis is the concerted product of the author and the supervisor, Zhou Xiaomo's three months of efforts. The author's keen thanks goes to her for her wellrounded instruction on this thesis. Her original ideas of literary criticism and appreciation have always stimulated the author to endeavour for accruing the habit of critical thinking and independent thinking in both completing this dissertation and her other academic tasks. Also, the knowledge regarding research approaches and literary theories that she conveyed to the author in this period can be termed as the treasure that the author will benefit from in her lifelong research and studying. Apart from that, the author will give her thanks to her friends, who have always kept discussing the thesis and the book with her. Last but not least, the author will give her sincere appreciation to her dear parents who have always been consoling and supporting her with absolute patience.

\section{REFERENCES}

[1] Hardy, Thomas. "Tess of the d'Urbervilles," Oxford: Oxford University Press; Beijing: Foreign language Teaching\&Research Press, 1980.

[2] Varley, Lang. "Crabbe and Tess of the D’Urbervilles,” Modern Language Notes, vol. 53, pp. 121-126, 1938.

[3] Breen, Melwyn. "Tess in the Theatre; Two Dramatizations of Tess of the D'Urbervilles," University of Toronto Quarterly, vol. 21, pp. 6774, 1952.

[4] Nie Zhenzhao "Thomas Hardy' A Study of His Novels," Central-China Normal University Press; Wuhan, 1992.

[5] John Rabbetts. "From Hardy to Faulkner," Spring Science and Business Media LLC, 1989. 